\title{
SPIRO-GRAPHIC AND THORACO-METRIC STUDIES IN PARAPLEGIC PATIENTS
}

\author{
By A. Maglio, A. Venerando, A. Dal Monte and F. Lamberti-Bocconi \\ Centro Paraplegici, I.N.A.I.L., Lido di Roma
}

Purpose of the Investigation. Research on the respiratory function of paraplegics is of great interest, not only because there are few data on this subject in the literature but also because such investigations may lead to the solution of some as yet unsolved problems of the physiopathology of respiration, as well as furnish useful indications in the field of paraplegia.

The analysis of data obtained by measurements of the excursions of the chest and diaphragm offers the opportunity to assess the possibilities of ventilatory kinetics both of the chest and of the diaphram with sufficient approximation.

We have thought it interesting to carry out investigations in paraplegics with the object of ascertaining whether the medullary lesion brings about changes in the kinetics of the diaphragm and of the ribs and to assess the extent of such changes. Such investigations are usually reserved for athletes or patients suffering from chest disease.

Material. A preliminary examination was carried out in 62 male paraplegics, aged 22-45, all hospitalised at the I.N.A.I.L. Centre for Paraplegics at Lido di Roma. Among these, 36 patients were selected who had their injury at least two years previously and whose paraplegia was stabilised. These patients were divided into two groups, the first of which comprised 24 paraplegics whose lesions were situated above the Ioth dorsal segment, while the second comprised I2 subjects whose lesions were situated below the Ioth dorsal segment and did not, therefore, involve the accessory expiratory muscles.

Methods. (I) Thoraco-Metric Investigations. In both groups, the chest circumference was measured at the level of the armpit and the xiphoid process; data concerning the dynamics of the diaphragm were also collected.

Weight and height of every subjects were also taken and the body surface was calculated. The mean values of these anthropometrics parameters were almost identical in the two groups.

For the measurement of the axillary and xiphoid chest circumference the technique described by Maccagno (1954, I960) in Dal Monte's modifications (1964) has been applied; the instruments used were a flexible curvilineal and an anthropometric gauge introduced by Viola.

The technique of measurement consisted of three phases. During the first one, four landmarks were established on the chest; the upper frontal one, situated at the point of intersection of the mid-sternal line with a horizontal plane passing through the highest point of the armpit; the upper back one, situated at the intersection of the same line with a plane passing through the xiphoid process of the sternum; lastly the lower frontal one, situated on the xiphoid process itself.

The second phase consisted of measuring the distances between the two upper and the lower landmarks during maximum inspiration and maximum expiration using the Viola's gauge. 
During the third phase the semi-circumferences of the left and right hemithorax were measured in the upper and lower planes in maximum inspiration and expiration by means of the flexible curvilineal. Plotting the changes of these circumferences on a piece of drawing-paper, the ovoid areas are obtained showing the excursions of the upper and lower parts of the chest.

(2) Phrenico-kinetic Investigations. The kinetics of the diaphragm have been followed by means of the fluoroscope. The position of the diaphragm during normal respiration and during maximum inspiration was traced on a sheet of plastic applied to the fluoroscope. Thus the phreno-expiratory, phreno-inspiratory and phreno-kinetic indices were obtained, indicating the respective distances: maximum expiration/normal expiration; maximum inspiration/normal inspiration; maximum expiration/maximum inspiration. The former two indices are the expression of the maximal possibilities of excursion of the diaphragm in expiration and inspiration, while the third one shows the possibility of excursion of the diaphragm in toto. From our experience the normal values of these indices are as follows: phreno-expiratory right: $3.00 \mathrm{~cm}$. , left: $3.10 \mathrm{~cm} . ;$ phreno-inspiratory right: I $.90 \mathrm{~cm}$., left: $2.50 \mathrm{~cm}$.; phreno-kinetic right: $4.90 \mathrm{~cm}$., left: $5.55 \mathrm{~cm}$.

In the upright position, the phreno-expiratory index prevails, i.e. there is a greater reserve of diaphragmatic movement available for deep expiration.

(3) Spirometric Investigations. The following spirometric indices were used for the assessment of respiratory efficiency:

Vital capacity (V.C.), both actual and theoretic.

Respiratory frequency.

Maximum voluntary ventilation per minute (M.V.V.).

Maximum expiratory volume per second (M.E.V.S.).

A Godard expirograph (type E.P. 6200I) was used for the determination of all the indices.

The determinations have been carried out under strictly basic conditions. For every subject the following data were collected: age, height and weight; the body surface was calculated.

The determinations have been carried out in the shortest possible period of time so as to reduce to a minimum errors due to climatic variations.

All the figures obtained by spirometry have been standardised by applying the B.T.B.S. correction with the object of ascertaining the correlation which was likely to exist.

Furthermore, the following parameters have been compared in the two groups: experimental V.C., M.E.V.S., theoretical V.C. and the ratio M.E.V.S./experimental V.C. $\times$ Ioo. (Tables I and II).

In order to evaluate the statistical significance of the differences between the mean values of the two groups, Student's test for small samples has been applied according to the following formula:

$$
t=\frac{X_{\mathrm{I}}-X_{2}}{\frac{D_{\mathrm{I}}+D_{2}}{g_{\mathrm{I}}+g_{2}} \cdot{\overline{N \mathrm{I}}+N_{2}}_{N \mathrm{I} \cdot N_{2}}} \mathrm{I} / 2
$$

where $X, D, g$ and $N$ represent the mean values, deviations, degrees of freedom and size of the two samples indicated by the indices I and 2, respectively. The results of this comparison are listed in Table III where $X_{1}$ and $X_{2}$ represent the mean 
values of the first and second group of paraplegics, respectively, $\Delta x$ represents the difference in favour of the first group: $t$ the index and $p$ the probability that both samples belong to the same population.

\section{TABLE I}

\begin{tabular}{|l|r|r|r|r|}
\hline Group I & V.C. Act. & M.E.V.S. & V.C. Theor. & M.E.V.S./V.C. Act. \\
\hline$\sum x$ & $88 \mathrm{I}$ & 749 & $\mathrm{I}, 022$ & \multicolumn{1}{c}{, 04I } \\
\hline$\sum x^{2}$ & 33,525 & 24,369 & 43,796 & $\mathrm{I} 75,096$ \\
$\left(\sum x\right)^{2}$ & $776, \mathrm{I} 6 \mathrm{I}$ & $56 \mathrm{I}, 00 \mathrm{I}$ & $\mathrm{I}, 0444,484$ & $4, \mathrm{I} 65,68 \mathrm{I}$ \\
$\left(\sum x\right)^{2} / n$ & 32,340 & 23,375 & 43,520 & $\mathrm{I} 73,570$ \\
$D$ & $\mathrm{I}, \mathrm{I} 9 \mathrm{I}$ & 994 & 276 & $\mathrm{I}, 526$ \\
$\sigma^{2}$ & $5 \mathrm{I} \cdot 78$ & $43 \cdot 2 \mathrm{I}$ & $\mathrm{I} 2 \cdot 00$ & $66 \cdot 34$ \\
$\sigma$ & $\mp 7 \cdot 19$ & $\mp 6 \cdot 57$ & $\mp 3 \cdot 47$ & $\mp 8 \cdot \mathrm{I} 4$ \\
$\bar{x}$ & $36 \cdot 70$ & $3 \mathrm{I} \cdot 20$ & $42 \cdot 58$ & $85 \cdot 04$
\end{tabular}

$\bar{\Sigma}=$ Sum. $\quad x=$ Variable. $\quad D=$ Deviation. $\sigma=$ Standard deviation. $\bar{x}=$ Mean values.

TABLE II

\begin{tabular}{|l|r|r|r|r}
\hline Group II & V.C. Act. & M.E.V.S. & V.C. Theor. & M.E.V.S. V.C. Act. \\
\hline$\sum x$ & 399 & 324 & 370 & 727 \\
$\sum x^{2}$ & $\mathrm{I} 7,975$ & $\mathrm{I} 2, \mathrm{IO}$ & $\mathrm{I} 5,304$ & 59,493 \\
$\left(\sum x\right)^{2}$ & $\mathrm{I} 59,20 \mathrm{I}$ & $\mathrm{I} 04,976$ & $\mathrm{I} 36,900$ & 528,529 \\
$\left(\sum x\right)^{2} / n$ & $\mathrm{I} 7,689$ & $\mathrm{I}, 664$ & $\mathrm{I} 5,2 \mathrm{I} \mathrm{I}$ & 58,725 \\
$D$ & 286 & 444 & 93 & 768 \\
$\sigma^{2}$ & 3,575 & 5,550 & $\mathrm{I}, \mathrm{I} 62$ & 9,600 \\
$\sigma$ & 598 & 745 & $34 \mathrm{I}$ & 980 \\
$\bar{x}$ & 4,433 & 3,600 & $4, \mathrm{II}$ & 8,077 \\
\hline
\end{tabular}

$\Sigma=$ Sum. $x=$ Variable. $D=$ Deviation. $\sigma=$ Standard deviation. $x=$ Mean values.

TABLE III

\begin{tabular}{|c|c|c|c|c|c|}
\hline Parameters & $X$ & $X_{1}$ & $\Delta x$ & $t$ & $P$ \\
\hline V.C. Actua & $44 \cdot 33$ & $36 \cdot 70 \mp 7 \cdot 19$ & $7 \cdot 63$ & $2 \cdot 84$ & $.005<>\cdot 0$ \\
\hline M.E.V.S & $36 \cdot 00 \mp 7 \cdot 45$ & $31 \cdot 20 \mp 6.57$ & $4 \cdot 80$ & $\mathrm{I} \cdot 8 \mathrm{I}$ & $.05<>\cdot I$ \\
\hline V.C. Theor. & $4 \mathrm{I} \cdot \mathrm{II} \mp 3 \cdot 4 \mathrm{I}$ & $42 \cdot 58 \mp 3 \cdot 47$ & $\mathrm{I} \cdot 47$ & $I \cdot 09$ & $\cdot 2<>\cdot 5$ \\
\hline M.E.V.S.V.C. $\%$ & $80 \cdot 77 \mp 9.80$ & $85.04 \mp 8 \cdot 14$ & $4 \cdot 27$ & $\mathrm{I} \cdot 27$ & $\cdot 2<>\cdot 5$ \\
\hline
\end{tabular}

V.C. actual = Actual vital capacity.

M.E.V.S. = Maximum voluntary ventilation per minute.

V.C. theor. = Theoretical vital capacity.

M.E.V.S./V.C. $=$ Ratio M.E.V.S. per actual V.C. $\times$ Ioo.

$X_{2}=$ Mean values of the group with lesions below Tio.

$X \mathrm{I}=$ Mean values of the group with lesions above TIO.

$\Delta x=$ Difference in favour of the group I.

$t=$ Index.

$P=$ Probability that both samples belong to the same population. 


\section{RESULTS AND COMMENTS}

Thoraco-metric and Phrenico-kinetic Investigations. Table IV shows the figures obtained in the first and second group of paraplegics examined. In order to give a detailed exposition of these parameters, the mean values of the left and right axillary and xiphoid semicircumferences were calculated separately for both groups.

TABLE IV

\begin{tabular}{|c|c|c|}
\hline Mean values & Above Tio & Below Tio \\
\hline Left & & \\
$\quad$ axillary cm. & 2.74 & 3.17 \\
xiphoid cm. & 2.97 & 3.01 \\
Right & & 2.97 \\
axillary cm. & 2.78 & 2.97 \\
xiphoid cm. & 2.79 & 3.20 \\
\hline
\end{tabular}

These mean values show that paraplegics of the first group (above Tio) have markedly reduced excursions in the axillary and xiphoid planes as compared to those of the second group (below Tio). The differences seemed to be most marked for the left axillary semicircumference, and less marked for the left xiphoid one.

Thus it may be concluded that in paraplegics suffering from a deficiency of their accessory muscles the dynamics of the rib movement in toto are deficient.

As for the kinetics of the diaphragm, the results of our investigations are given in Table V.

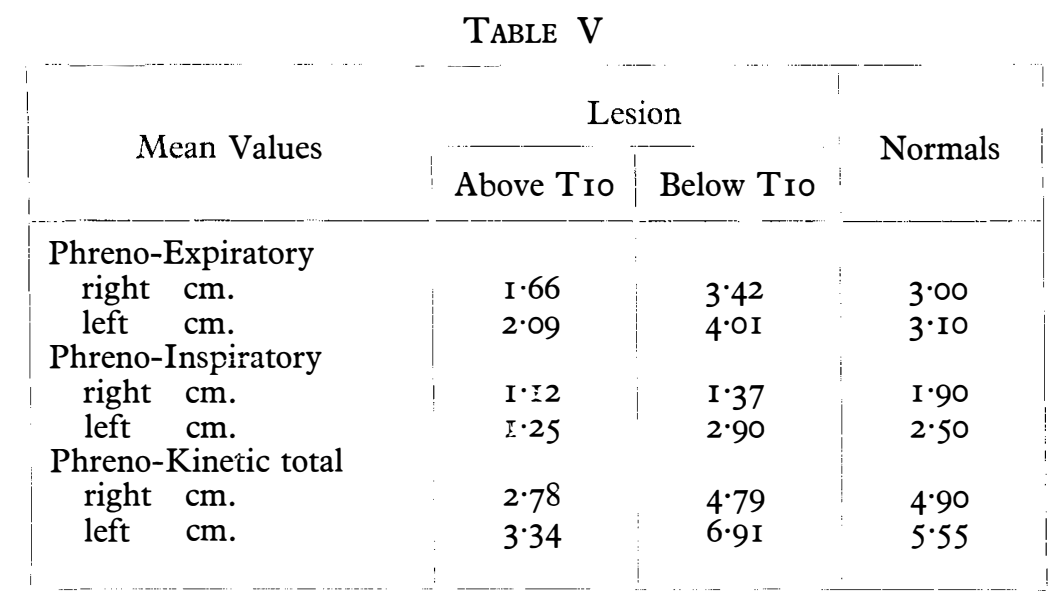

In both groups the mean phreno-expiratory index is higher, both on the right and on the left than the phreno-inspiratory one, exactly as is the case in normal subjects. Nevertheless, in the first group of paraplegics the mean values of the expiratory phreno-kinetic index is considerably below normal, amounting only to $2.09 \mathrm{~cm}$. on the left and $\mathrm{I} .66 \mathrm{~cm}$. on the right. On the other hand in the second group the mean value for this index was found to be above the normal mean. 
In the first group of paraplegics, the phreno-inspiratory index is below normal for both sides, while in the second group it is within normal limits with a marked excess in favour of the left hemidiaphragm. On the other hand, the right hemidiaphragm shows a comparatively smaller excursion in this group of patients.

Obviously, the behaviour of the left and right expiratory and inspiratory phreno-kinetic indices finds expression also in the total phreno-kinetic indices for both sides and for both groups of paraplegics.

Thus, the results of our investigations lead to the conclusion that there is a marked deficiency in the respiratory dynamics of the ribs as well as in the kinetics of the diaphragm in paraplegics whose spinal injuries are situated above the roth thoracic segment. Paraplegics with lesions below that level show larger excursions, both at the axillary and at the xiphoid level, than those found in the first group.

On the other hand, the excursions of the diaphragm are comparable to those of normal subjects and even, as far as the left hemidiaphragm is concerned, superior. In our opinion, this is due to the favourable results of the intensive respiratory and motor physiotherapy to which all our patients had been submitted.

Spirographic Investigations. The statistical analysis of our data leads to the conclusion that experimental V.C. is markedly higher in the group of paraplegics whose lesions are situated below the Ioth thoracic segment. The M.E.V.S., too, is higher in this group but not to an extent proportional to the V.C. (Table III).

The most interesting finding while confirming the foregoing is obtained by the comparison of the ratio: M.E.V.S./experimental V.C. In fact, this comparison shows a marked increase in the medium value of the second group as compared to the first.

These findings show a marked respiratory deficit in paraplegics whose lesions are above the Ioth dorsal segment. On closer analysis this deficit must be attributed largely to a reduction of the V.C. and to a lesser degree to a reduction of the M.E.V.S. This must be considered to be due to non-functioning of the various groups of muscles which normally take part in the maximal ventilatory excursion during the phases of maximal inspiration and expiration.

Among the dynamics respiratory indices the M.E.V.S. is the most indicative one and its behaviour lends itself to some suggestive interpretations. In comparison with the experimental V.C., the values for M.E.V.S. are no doubt high and compare well, in terms of percentage, with those found in healthy trained subjects.

As compared with theoretical V.C. the values M.E.V.S. are on the contrary below normal. This behaviour of the M.E.V.S. goes to show that paraplegics with high medullary lesions maintain a satisfactory respiratory efficiency in spite of the deficit of the muscles forming the abdominal pressure during the central phase of the respiratory excursion though on the whole they use their residual respiration volumes almost entirely.

It would thus appear that the paraplegic with high medullary lesions and therefore with involvement of the expiratory muscles uses the greatest part of his ventilatory capacity.

Obviously during the expiratory phase, apart from muscular action, the intrinsic elasticity of the lungs comes into play. This, too, is likely to be enhanced by a comparison of theoretical and experimental V.C. in the second group of our patients. These patients who do not present a deficit of the accessory expiratory muscles show in fact mean values of experimental V.C. which are far above the 
theoretical ones calculated according to Baldwin et al. (1948). This is in accordance with the results of Grossiord et al. (1963).

The validity of this conclusion is further borne out by the behaviour of the ratio: M.E.V.S./theoretical V.C. per cent., which does not differ from what is considered the mean physiological value.

\section{SUMMARY}

The respiratory function of two groups of paraplegics, with lesions above and below Tio, has been studied.

Excursions of the chest, excursions of the diaphragm and spirographic investigations have been carried on.

The conclusions are that there is a marked deficiency in the respiratory dynamics of the ribs as well as in the kinetics of the diaphragm in paraplegics whose spinal injuries are situated above the roth thoracic segment. The spirographic investigations therefore show that paraplegics with high lesions maintain a satisfactory respiratory efficiency in spite of the deficit of the abdominal muscles, though on the whole they use their residual respiratory volumes almost entirely.

\section{RÉSUMÉ}

Il a été étudié la fonction respiratoire de deux groupes de paraplégiques atteints de lésions supérieures et inférieures à $\mathrm{T}$ IO.

Les oscillations de la poitrine, les oscillations du diaphragme et les recherches spirographiques ont menées.

Les conclusions sont qu'il y a une profonde deficience dans la dynamique respiratoire des côtes aussi bien que dans la cynétique du diaphragme lorsqu'il s'agit de paraplégiques dont les lésions sont supérieures à la dixième segment thoracale.

C'est pourquoi les recherches spirographiques tendent à montrer que les paraplégiques atteints de lésions hautes maintiennent une efficacité respiratoire satisfaisante en dépit des muscles abdominaux, bien que dans l'ensemble ils utilisent presque entièrement leurs volumes respiratoires restants.

\section{ZUSAMMENFASSUNG}

Die respiratorische Funktion zweier Gruppen von Paraplegikern mit Läsionen oberhalb und unterhalb T.Io wurde untersucht.

Es wurden Exkursionen des Brustkorbes, des Zwerchfells sowie spirographische Untersuchungen ausgeführt, die eine deutliche respiratorische Insuffizienz der Dynamik der Rippen sowie der Kinetik des Zwerchfells bei Paraplegikern mit Läsionen oberhalb T.ı ergaben.

Die spirographischen Untersuchungen zeigten eine befriedigende respiratorische Leistungsfähigkeit bei hohen Läsionen trotz der Lähmung der Bauchmuskeln.

\section{REFERENCES}

Baldwin, E. de F., Cournaud, A. \& Richards, D. W. Jr. (1948). Medicine, 27, 243.

Dal Monte, A. (1964). Med. sportiva, 4, i I.

Grossiond, A. et autres (1963). Sem. Hôp. Paris, 39, 663.

Maccagno, A. L. (1954). Riv. Tuberc. 2, 255.

MACCAGNO, A. L. (I960). Esperienze sulla valutazione funzionale respiratoria degli atleti. Atti Simposi 1960 di Medicina Sportiva. G. Mendel. 